\title{
ELEMENTS OF THE S-GENE COMPLEX \\ IV. S-ALLELE POLYMORPHISM IN NICOTIANA SPECIES
}

KAMLA KANT PANDEY

Grasslands Division, D.S.I.R., Palmerston North, New Zealand

Received 20.xii.68

\section{INTRODUCTION}

IN plants, genetic polymorphism has been studied mainly in connection with albinism, leaf markings, cyanogenesis and sex (Ford, 1940; Corkill, 1942; Lewis, 1949; Baker, 1954; Godley, 1955; Daday, 1958; Apirion and Zohary, 1961; Davies, 1963; Crowe, 1964). Unlike animals, plants have very diverse and complex breeding systems (Darlington and Mather, 1949; Stebbins, 1950; Darlington, 1958). Sexual polymorphisms concerning dioecy, gynodioecy and heteromorphic incompatibility are distinguishable by their morphological features. However, the problems of sexual reproduction, and hence of evolution and survival, posed by the sedentary nature of plants, have been solved, in nature, only partly on the morphological level. Perhaps by far the most significant evolutionary development in plants to meet this serious handicap has been on the physiological level, with the development of homomorphic self-incompatibility systems, in which there are no specific morphological differences between plants. Although the $S$ gene controlling homomorphic incompatibility has a large number of alleles, the intraspecific equivalency of the incompatibility alleles has discouraged its serious consideration in the discussion of polymorphism. Recent studies showing polymorphism of $S$ alleles in the control of interspecific incompatibility in Nicotiana (Pandey, 1964, 1967a) have opened a fresh approach to this problem.

Preliminary investigations have shown that in the self-incompatible (S.I.) species $\mathcal{N}$. alata, $\mathcal{N}$. bonariensis and $\mathcal{N}$. noctiflora, styles containing different $S$ alleles vary in their ability to accept or reject the pollen of the sister selfcompatible (S.C.) species $\mathcal{N}$. langsdorffi. In $\mathcal{N}$. bonariensis the $S$ alleles also show polymorphism when tested with the pollen of the S.I. species $\mathcal{N}$. noctiflora, and with the pollen of the S.I. strain GM8 of otherwise S.C. species $\mathcal{N}$. glauca.

Of the 64 species in the genus Nicotiana, only six, all diploids, are S.I.: $\mathcal{N}$. alata, $\mathcal{N}$. noctiflora, $\mathcal{N}$. bonariensis, $\mathcal{N}$. petunioides, $\mathcal{N}$. forgetiana and $\mathcal{N}$. tomentosa (Goodspeed, 1954; Burbidge, 1960; Smith, 1968). In the present experiments five of these S.I. species (excluding $\mathcal{N}$. tomentosa) have been investigated for $S$ allele polymorphism. The results show parallel polymorphism occurring in all S.I. species and throw considerable light on the structure and evolution of the $S$ complex.

\section{Materials ANd methods}

Seeds of S.C. South American species $\mathcal{N}$. glutinosa $(n=12), \mathcal{N}$. glauca $(n=12)$ (the usual strain called here " $\mathrm{G} "), \mathcal{N}$. sylvestris $(n=12), \mathcal{N}$. paniculata $(n=12), \mathcal{N}$. tabacum $(n=24)$ and $\mathcal{N}$. rustica $(n=24)$, were $2 \mathrm{Q}$ 
obtained from various Botanical Gardens and research institutes (Pandey, 1964). Seed of one Australian species, $\mathcal{N}$. suaveolens $(n=16)$, was obtained from Commonwealth Scientific and Industrial Research Organization, Canberra, Australia. The sources of the seeds of the five S.I. species and that of the two main testers, $\mathcal{N}$. langsdorffi and $\mathcal{N}$. glauca strain GM8, involved in the determination of polymorphism, have been given in table 1 . The

TABLE 1

\begin{tabular}{|c|c|c|}
\hline \multicolumn{3}{|c|}{ Sources of seed materials } \\
\hline $\begin{array}{l}\text { Species } \\
\text { (Chromosome no.) }\end{array}$ & Family no. & Seed source \\
\hline $\begin{array}{l}\mathcal{N} \text {. bonariensis } \\
\quad(n=9)\end{array}$ & $\begin{array}{l}8746 \\
9503 \\
9584 \mathrm{a} \\
9584 \mathrm{~b}\end{array}$ & $\begin{array}{l}\text { U.S.D.A., Beltsville, Maryland, U.S.A. } \\
\text { University of California, Berkeley, U.S.A. } \\
\text { C.S.I.R.O., Canberra, Australia. } \\
\text { Tobacco Research Station, Motueka, New } \\
\text { Zealand. }\end{array}$ \\
\hline $\begin{array}{l}\mathcal{N} . \text { forgetiana } \\
\quad(n=9)\end{array}$ & $\begin{array}{l}9586 \\
9620\end{array}$ & $\begin{array}{l}\text { C.S.I.R.O., Canberra, Australia. } \\
\text { U.S.D.A., Beltsville, Maryland, U.S.A. }\end{array}$ \\
\hline $\begin{array}{l}\mathcal{N} \text {. alata } \\
\quad(n=9)\end{array}$ & - & $\begin{array}{l}\text { Several genotypes were obtained from seeds of two } \\
\text { sources, Instituto ed Orto Botanico dell } \\
\text { 'Universita, Modena, Italy, and Institut } \\
\text { Pflanzenbau, Geisenheim, Rheingau, Germany. } \\
\text { Homozygous genotypes were produced through } \\
\text { bud-self-pollination (Pandey, 1963). }\end{array}$ \\
\hline $\begin{array}{r}\mathcal{N} . \text { noctiflora } \\
\quad(n=12)\end{array}$ & $\begin{array}{c}8755 \\
9501 \\
9516,9517,9562\end{array}$ & $\begin{array}{l}\text { U.S.D.A., Beltsville, Maryland, U.S.A. } \\
\text { University of California, Berkeley, U.S.A. } \\
\text { Families raised from seeds obtained from crosses } \\
\text { between plants of the family } 8755 \text {. }\end{array}$ \\
\hline $\begin{array}{l}\mathcal{N} . \text { petunioides } \\
\quad(n=12)\end{array}$ & $\begin{array}{l}8751 \\
9515\end{array}$ & $\begin{array}{l}\text { U.S.D.A., Beltsville, Maryland, U.S.A. } \\
\text { Family grown from seeds of a cross between two } \\
\text { plants of the family } 8751 \text {. }\end{array}$ \\
\hline $\begin{array}{l}\text { N. glauca } \\
\text { strain GM8 } \\
(n=12)\end{array}$ & 一 & $\begin{array}{l}\text { A bright red-flowered self-incompatible strain } \\
\text { found among plants grown from the seeds } \\
\text { obtained from Instituto Botanica Agricola, } \\
\text { Castelar, Argentina. }\end{array}$ \\
\hline
\end{tabular}

N. langsdorffii $\quad-\quad$ Royal Botanic Gardens, Kew, England.

$(n=9)$

third strain of $\mathcal{N}$. glauca, N29, occurred in the seed material received from Argentina, from which the S.I. strain GM8 was obtained, and differed from the usual strain $\mathrm{C}$ in having a slightly bigger corolla, with more prominent throat cylinder and limb.

A description of the growing conditions of plants, and of the pollination and cytological techniques, has been given in earlier papers (Pandey, 1964, $1967 a, b)$.

\section{Results}

In the earlier preliminary experiments polymorphism of $S$ alleles in S.I. species was revealed in crosses with the pollen of the S.C. species $\mathcal{N}$. langsdorffii (N.1.) and the S.I. strain GM8 of S.C. species $\mathcal{N}$. glauca (Pandey, 1967a). In the first stage of the present experiments, therefore, plants of 
different S.I. species were crossed with the pollen of only these two testers. In these crosses four kinds of compatibility relationships are possible, thus dividing the plants into four groups (henceforth called "polymorphic classes"):

A-Incompatible with N.1. and compatible with GM8.

B-Compatible with N.1. and incompatible with GM8.

C-Compatible with both N.1. and GM8.

D-Incompatible with both N.1. and GM8.

In the second stage of the experiments plants of each species were crossed with representatives of different polymorphic classes of the other species, revealed by the first stage of the experiments.

(a) $\mathcal{N}$. alata

\section{(i) Polymorphic classes in different S.I. species}

The results of crosses between $\mathcal{N}$. alata and N.l. have been reported previously (Pandey, 1964). Two kinds of plants were obtained in $\mathcal{N}$. alata: styles of one $(\mathrm{N})$, having the $S_{\mathrm{I}}$ type of incompatibility allele, accepted the

TABLE 2

Summary of results from the four families of $\mathrm{N}$. bonariensis giving the number of plants in incompatibility groups, and polymorphic classes, found in each family, respectively

\begin{tabular}{|c|c|c|c|c|c|c|}
\hline \multirow[b]{2}{*}{$\begin{array}{c}\text { Family } \\
\text { No. }\end{array}$} & \multicolumn{6}{|c|}{$\begin{array}{l}\text { No. of plants in intraincompatible } \\
\text { intercompatible groups } \\
\text { (Polymorphic classes) }\end{array}$} \\
\hline & $\begin{array}{c}\text { I } \\
\text { (A) }\end{array}$ & $\begin{array}{l}\text { II } \\
\text { (B) }\end{array}$ & $\begin{array}{l}\text { III } \\
\text { (C) }\end{array}$ & $\begin{array}{l}\text { IV } \\
\text { (D) }\end{array}$ & $\begin{array}{c}\mathrm{V} \\
\text { (D) }\end{array}$ & $\begin{array}{l}\text { VI } \\
\text { (B) }\end{array}$ \\
\hline 8746 & 6 & 17 & 6 & - & - & - \\
\hline 9503 & - & 8 & 3 & 19 & 6 & 一 \\
\hline $9584 a$ & 1 & - & 2 & 5 & - & 2 \\
\hline $9584 b$ & 6 & 3 & 2 & 10 & 一 & - \\
\hline
\end{tabular}

N.1. pollen while styles of the other $(\mathrm{M})$, having the $S_{\mathrm{FI}}$ type of allele, rejected this pollen. Grosses of three plants of each of the five $S$ genotypes of $\mathcal{N}$. alata $\left(S_{1} S_{1}, S_{2} S_{2}, S_{3} S_{3}, S_{\mathrm{F} 10} S_{\mathrm{F} 10}\right.$ and $\left.S_{\mathrm{F} 11} S_{\mathrm{F} 11}\right)$ with GM8 revealed no difference between plants: GM8 pollen was universally rejected. Thus, considering the results of the two testers together, two polymorphic classes, B and $\mathrm{D}$, were distinguished in $\mathcal{N}$. alata. In the reciprocal crosses, $\mathcal{N}$. alata pollen was universally compatible on both N.1. and GM8 styles.

\section{(b) $\mathcal{N}$. bonariensis}

Table 2 gives the results of reciprocal crosses of the two testers with the plants of four families 8746 (reported in detail earlier, Pandey, 1967a), 9503, 9584a and 9584b respectively, derived from seeds from different sources. As male parents, all plants of $\mathcal{N}$. bonariensis were compatible with both testers. As female parents, however, they fell into different polymorphic classes. In the family 9503 there were three classes: B (8 plants), $\mathrm{C}(3)$, and D (25). All the four classes were represented in the families 9584a: A (1), B (2), C (2) and D (5); and 9584b: A (6), B (3), C (2) and D (10). 
When plants of each family were crossed among themselves, they fell into 3 or 4 intraincompatible intercompatible groups. With one exception, the incompatibility groups in each family were identical with the polymorphic classes. The exception occurred in the family 9503, where the class D was composed of two intraincompatible intercompatible groups.

Crosses between incompatibility groups of different families revealed the presence of common groups between them. There were altogether only six incompatibility groups (I-VI) which between them had only four different $S$ alleles. This suggests that the seed materials from the four sources had a common origin probably from a set of two plants differing in both alleles.

\section{(c) $\mathcal{N}$. noctiflora}

In this species two families of plants, 8755 and 9501, have been studied. The family 8755, reported earlier (Pandey, 1967a), comprised nine plants and had two intraincompatible intercompatible groups, I (4) and II (5). The

TABLE 3

Summary of results from the two families of $\mathrm{N}$. noctiflora giving the number of plants in incompatibility groups (with proposed genetic constitution), and polymorphic classes, found in each family respectively

\begin{tabular}{|c|c|c|c|}
\hline \multirow[b]{2}{*}{ Family } & \multicolumn{3}{|c|}{$\begin{array}{l}\text { No. of plants in intraincompatible } \\
\text { intercompatible groups } \\
\text { (Polymorphic classes) }\end{array}$} \\
\hline & $\mathrm{I}-S_{(\mathrm{A})} S_{2}$ & $\mathrm{II} \underset{(\mathrm{C})}{-S_{1} S_{3}}$ & $\begin{array}{l}\mathrm{III}-S_{2} S_{3} \\
\text { (A) }\end{array}$ \\
\hline 8755 & 4 & 5 & - \\
\hline 9501 & - & 12 & 6 \\
\hline
\end{tabular}

incompatibility groups I and II were identical with the polymorphic classes $A$ and $\mathrm{C}$ respectively, distinguished on the basis of crosses with the two testers.

In the second family 9501 , also, two intraincompatible intercompatible groups, comprising 12 and 6 plants respectively, were distinguished. Intercrosses of the four groups showed that the two families had one group in common, the group with 12 plants in the family 9501 being identical with the group II of the family 8755, and the group with 6 plants forming a new group (III).

The results again suggest that, as in the case of $\mathcal{N}$. bonariensis, the seeds from the two sources were related. In fact, the cross-incompatibility data from the two families of $\mathcal{N}$. noctiflora are in perfect agreement with the assumption that the seeds from these two sources had their origin from respective reciprocal crosses between two plants only, which had one allele in common. The three incompatibility groups may be represented by the following $S$ genotypes: I $-S_{1} S_{2}$, II $-S_{1} S_{3}$, and III $-S_{2} S_{3}$.

The data on polymorphism and incompatibility groups are summarised in table 3. They show that, as in $\mathcal{N}$. bonariensis, the plants of the same incompatibility group fall into the same polymorphic class. Again, as in $\mathcal{N}$. bonariensis, there are two incompatibility groups (I and III), which belong to the same polymorphic class (A). Thus while there are only two polymorphic classes, both resprented in each family, there are three incompatibility groups. The data on polymorphism can be explained on the assumption 
that one of the three $S$ alleles, in the present case $S_{2}$, involved in these plants, like the $S_{\mathrm{FI}}$ alleles in $\mathcal{N}$. alata (Pandey, 1964), when present in the style, causes the rejection of the N.I. pollen, whereas styles having the other $S$ alleles accept such pollen.

\section{(d) $\mathcal{N}$. petunioides}

Plants of one family, 8751, comprising 27 plants, were reciprocally crossed with the two testers. Two polymorphic classes, B (10) and D (17), were distinguished. All crosses with testers as the female parents were compatible (table 4). Intraspecific crosses to distinguish incompatibility groups within the family were not made.

\section{TABLE 4}

Polymorphic classes in N. petunioides and N. forgetiana

\begin{tabular}{|c|c|c|c|c|}
\hline \multirow[b]{2}{*}{$\begin{array}{c}\text { Species } \\
\text { and family }\end{array}$} & \multicolumn{4}{|c|}{$\begin{array}{l}\text { No. of plants in different } \\
\text { polymorphic classes }\end{array}$} \\
\hline & A & B & G & $\mathrm{D}$ \\
\hline \multicolumn{5}{|l|}{$\mathcal{N}$. petunioides } \\
\hline 8751 & - & 10 & 一 & 17 \\
\hline \multicolumn{5}{|l|}{$\mathcal{N}$. forgetiana } \\
\hline 9586 & 一 & 17 & 一 & 15 \\
\hline 9620 & 一 & 18 & 一 & - \\
\hline
\end{tabular}

\section{(e) $\mathcal{N}$. forgetiana}

Many of the plants studied in this species (26 out of 32 in the family 9586 and 7 out of 18 in 9620 ) were partly or fully S.C. All crosses with testers as the female parents were compatible. In the family 9586 the plants fell equally into two polymorphic classes, $\mathrm{B}(17)$ and $\mathrm{D}(15)$ ( $c f$. table 4 ). Owing to the high self-compatibility plants could not be separated into distinct incompatibility groups. However, when 27 (B-13 and D-14) of these plants were intercrossed, cross-incompatibility was almost wholly limited to the crosses in which both parents belonged to the same polymorphic class. Only one out of 122 crosses involving plants of the different polymorphic classes did not set a good-sized fruit, while 25 out of 101 crosses involving plants of the same class either did not set any fruit at all, or set very small fruits (pollen-tubes were not examined). These results suggest that the polymorphic classes in $\mathcal{N}$. forgetiana also, as in $\mathcal{N}$. bonariensis and $\mathcal{N}$. noctiflora, are closely associated with the incompatibility groups. However, crosses among plants of the family 9620 also revealed two incompatibility groups, although, as also found in rare cases in $\mathcal{N}$. bonariensis and $\mathcal{N}$. noctiflora, all plants belonged to the same polymorphic class (B).

\section{(ii) Crosses between representatives of polymorphic classes in different species}

(a) N. bonariensis tested with $\mathrm{N}$. petunioides and N. forgetiana

Eight plants of $\mathcal{N}$. bonariensis belonging to three polymorphic classes $\mathrm{A}(2$ plants, incompatibility group I), B (2, II) and C (4, III), were reciprocally crossed with 16 plants of $\mathcal{N}$. petunioides, belonging to classes B (4) and D (12). All crosses with $\mathcal{N}$. petunioides as the female parents were compatible. The 
results of crosses when $\mathcal{N}$. bonariensis plants were the female parents are given in table 5. The plants belonging to classes $\mathrm{A}$ and $\mathrm{C}$ were compatible with $\mathcal{N}$. petunioides while those of class B were incompatible. There were five crosses involving a plant (22) of class B which produced small fruits. However, all five of these crosses involved as the male parents $\mathcal{N}$. petunioides plants

TABLE 5

Results of crosses between $\mathrm{N}$. bonariensis (plants of 3 polymorphic classes) as females and N. petunioides (plants of 2 polymorphic classes) as males

$\mathcal{N}$. bonariensis

(Fa. 8746)

우

$\overbrace{\begin{array}{c}\text { Group } \\ \text { (Class) }\end{array} \quad}^{\text {No. }}$

I 1

(A) 36

II 22

(B) 24

III 21

(C) $\quad 25$

28

31

đN. petunioides plant numbers

\begin{tabular}{|c|c|c|c|c|c|c|c|c|c|c|c|c|c|c|c|}
\hline \multicolumn{4}{|c|}{ Polymorphic class B } & \multicolumn{12}{|c|}{ Polymorphic class D } \\
\hline 13 & 16 & 25 & 27 & 10 & 11 & 14 & 15 & 17 & 18 & 19 & 20 & 21 & 24 & 26 & 28 \\
\hline+ & + & + & + & + & + & + & + & + & + & + & + & + & + & + & + \\
\hline+ & + & + & + & + & + & + & + & + & + & + & + & + & + & + & + \\
\hline- & - & - & - & - & - & & $+*$ & - & - & $t^{*}$ & $+*$ & $+*$ & - & $+*$ & - \\
\hline- & - & - & - & - & - & - & - & - & - & - & - & - & - & - & - \\
\hline+ & + & + & + & + & + & + & + & + & + & + & + & + & & & + \\
\hline+ & + & + & + & + & + & + & + & + & + & + & + & + & + & + & + \\
\hline+ & + & + & + & + & + & + & + & + & + & + & + & + & + & + & + \\
\hline+ & + & + & + & + & + & + & + & + & + & + & + & + & + & + & + \\
\hline
\end{tabular}

* In these crosses the male parents were partly self-compatible.

which were partly S.C. All the other $\mathcal{N}$. petunioides plants used as the male parents were S.I., and were consistently cross-incompatible with class B plants of $\mathcal{N}$. bonariensis.

In a second experiment one plant from each of six incompatibility groups of $\mathcal{N}$. bonariensis was reciprocally crossed with one plant from each of the two

\section{TABle 6}

Results of reciprocal crosses of one plant from each of the six incompatibility groups in $\mathrm{N}$. bonariensis with one plant from each of the two polymorthic classes in each of the two species $\mathrm{N}$. petunioides and $\mathrm{N}$. forgetiana

\section{$\mathcal{N}$. petunioides class and plant numbers}

\begin{tabular}{crl}
\multicolumn{3}{c}{$\mathcal{N}$. bonariensis } \\
Class & Group & Pl. No. \\
A & I & $8746-1$ \\
B & II & $8746-5$ \\
C & III & $8746-8$ \\
D & IV & $9503-5$ \\
D & V & $9503-15$ \\
B & VI & $9584 a-6$
\end{tabular}

\begin{tabular}{|c|c|c|c|}
\hline \multicolumn{2}{|c|}{$\begin{array}{c}\text { B } \\
9515-1\end{array}$} & \multicolumn{2}{|c|}{$\underset{8751-10}{D}$} \\
\hline & & & \\
\hline 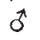 & 우 & $\sigma$ & q \\
\hline+ & + & + & + \\
\hline- & + & - & + \\
\hline+ & + & + & + \\
\hline- & + & - & + \\
\hline+ & + & + & + \\
\hline- & + & - & + \\
\hline
\end{tabular}

$\mathcal{N}$. forgetiana class and plant numbers

\begin{tabular}{|c|c|c|c|}
\hline \multirow{2}{*}{\multicolumn{2}{|c|}{$\begin{array}{c}\text { B } \\
9586-9\end{array}$}} & \multirow{2}{*}{\multicolumn{2}{|c|}{$\underset{9586-7}{D}$}} \\
\hline & & & \\
\hline & & & \\
\hline$\sigma$ & q & $\sigma$ & 우 \\
\hline+ & + & + & + \\
\hline- & + & - & + \\
\hline+ & + & + & + \\
\hline- & + & - & + \\
\hline+ & + & + & + \\
\hline+ & + & + & + \\
\hline
\end{tabular}

classes in each of the two species $\mathcal{N}$. petunioides and $\mathcal{N}$. forgetiana. The results are given in table 6 . As male parents all $\mathcal{N}$. bonariensis plants were compatible with both species; as female parents, however, the plants of incompatibility groups I, III and V were compatible and those of II and IV 
incompatible. The plant of group VI was incompatible with $\mathcal{N}$. petunioides but compatible with $\mathcal{N}$. forgetiana. Thus the two groups IV and V which belong to the same polymorphic class when tested with N.l. and GM8 have a different polymorphic pattern when tested with $\mathcal{N}$. petunioides and $\mathcal{N}$. forgetiana. Similarly, the two groups II and VI have similar polymorphic patterns when tested with N.l., GM8 and $\mathcal{N}$. petunioides, but differ when tested with $\mathcal{N}$. forgetiana. This shows that (1) polymorphism is based on $S$-allele genotype and that several $S$ genotypes may show the same polymorphic pattern; and (2) polymorphic classes distinguished in a species may differ from one group of testers to another.

\section{TABLE 7}

Results of reciprocal crosses of four plants from each of the three incompatibility groups in N. noctiflora with one plant from each of the six incompatibility groups in N. bonariensis, and also with one plant of N. petunioides

$\mathcal{N}$. bonariensis groups and plant numbers

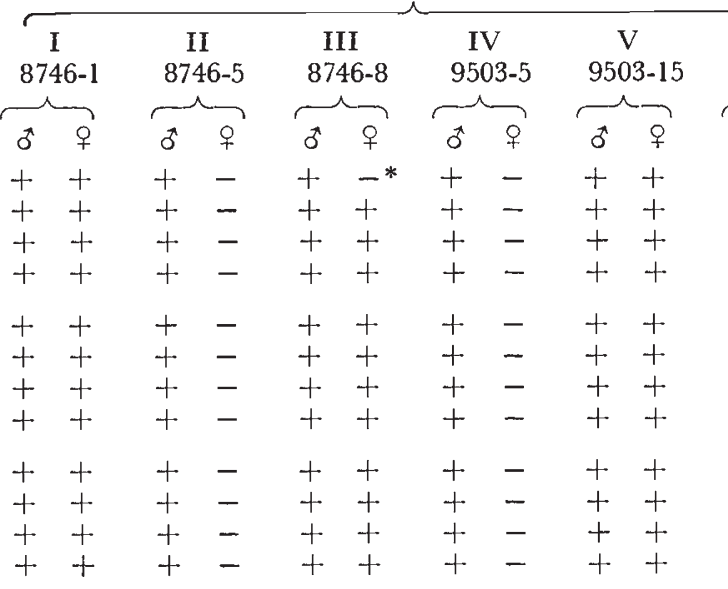

* Cause of this incompatibility is unknown.
N. petunioides

Class and Pl. No.



(b) N. bonariensis tested with $\mathrm{N}$. alata

The six groups of $\mathcal{N}$. bonariensis were used, as in the above experiment, in crosses with five different $S$ genotypes of $\mathcal{N}$. alata. All crosses with $\mathcal{N}$. bonariensis as the male parents were compatible. The crosses with $\mathcal{N}$. alata as the male parents, however, were inconclusive, owing to the extreme disparity between the stylar lengths of the two parents. Although most crosses produced fruits with varying amounts of seed, the cytological studies showed that in many cases there was only a partial penetration of the style by the pollen-tubes during the first two days after pollination. Apparently, in most cases some of the slow growing incompatible pollen-tubes were still able to effect fertilisation, due to the extremely short stylar length of $\mathcal{N}$. bonariensis as compared to that of $\mathcal{N}$. alata.

(c) N. noctiflora tested with $\mathrm{N}$. bonariensis, N. petunioides and N. alata

Four plants of each of the three incompatibility groups I (polymorphic class A), II (C), and III (A), in $\mathcal{N}$. noctiflora were reciprocally crossed with one plant of each of the six incompatibility groups in $\mathcal{N}$. bonariensis, and with one plant $(\mathrm{B})$ of $\mathcal{N}$. petunioides. The results, given in table 7 , show poly- 
morphism in $\mathcal{N}$. bonariensis but not in $\mathcal{N}$. noctiflora and $\mathcal{N}$. petunioides. $\mathcal{N}$. noctiflora plants were reciprocally compatible with $\mathcal{N}$. petunioides, and compatible as females with $\mathcal{N}$. bonariensis. As males, they were compatible with groups I, III and V, and incompatible with groups II, IV and VI, of $\mathcal{N}$. bonariensis.

The polymorphism in $\mathcal{N}$. bonariensis was completely associated with its genotypic constitution, except for one cross in the group III ( $q \mathcal{N}$. bon. $8746-8 \times \mathcal{N}$. noct. 9517-1-cf. table 7) which showed incompatibility instead of, as was normal for this group, compatibility. This result was peculiar to the specific parental combination and had no relationship with the $S$ constitution, for the same $\mathcal{N}$. bonariensis plant was compatible in crosses with other $\mathcal{N}$. noctiflora plants having the same $S$ constitution as the original male parent.

Crosses between $\mathcal{N}$. noctiflora and $\mathcal{N}$. alata (involving eight $S$ genotypes $\left(S_{1} S_{1}, S_{2} S_{2}, S_{3} S_{3}, S_{\mathrm{F} 10} S_{\mathrm{F} 10}, S_{\mathrm{F} 11} S_{\mathrm{F} 11}, S_{\mathrm{F} 10} S_{\mathrm{F} 11}, S_{1} S_{\mathrm{F} 10}\right.$ and $\left.S_{3} S_{\mathrm{F} 10}\right)$ were universally compatible when the latter was the male parent. The reciprocals,

TABLE 8

Polymorphic patterns in N. bonariensis: Summary of the results of crosses of the five incompatibility

\begin{tabular}{|c|c|c|c|c|c|c|}
\hline \multicolumn{2}{|c|}{$\underbrace{\begin{array}{c}\mathcal{N} . \\
\text {. }\end{array}}_{\text {bonariensis }}$} & \multirow[b]{2}{*}{\begin{tabular}{c}
$\mathcal{N}$. \\
langsdorffii \\
\multirow{\delta}{*}{}
\end{tabular}} & \multirow[b]{2}{*}{$\begin{array}{c}\mathcal{N} . \\
\text { glauca } \text { GM8 } \\
\hat{\delta}\end{array}$} & \multirow[b]{2}{*}{$\begin{array}{c}\mathcal{N} . \\
\text { petunioides } \\
\sigma^{*}\end{array}$} & \multirow[b]{2}{*}{$\begin{array}{c}\mathcal{N} . \\
\text { noctiflora } \\
\hat{\sigma}^{*}\end{array}$} & \multirow[b]{2}{*}{\begin{tabular}{c}
$\mathcal{N}$. \\
forgetiana \\
\multirow{0}{*}{}
\end{tabular}} \\
\hline Class & Group & & & & & \\
\hline A & I & - & + & + & + & + \\
\hline B & II & + & - & - & - & - \\
\hline C & III & + & + & + & + & + \\
\hline D & IV & - & - & - & - & - \\
\hline D & V & - & - & + & + & + \\
\hline B & VI & + & - & - & - & + \\
\hline
\end{tabular}

when $\mathcal{N}$. noctiflora was the male parent, were universally incompatible. The strength of incompatibility, as measured by the extent of pollen-tube growth in the $\mathcal{N}$. alata styles varied greatly, according to the type of allele present in the style. In all styles containing an $S_{\mathrm{FI}}$ type of allele, whether in the homozygous or heterozygous condition, inhibition usually occurred in the stigma. In styles containing only $S_{I}$ type of alleles, however, inhibition was very variable, in some cases pollen-tubes reaching more than half length of the style in 48-72 hours.

In the preliminary experiments (Pandey, 1967a), when S.I. $S$ genotypes extracted from the hydrids of $\mathcal{N}$. alata (S.I.) and $\mathcal{N}$. langsdorffi (S.C.), and having shorter styles than $\mathcal{N}$. alata, were used instead of pure $\mathcal{N}$. alata plants, certain genotypes were compatible with $\mathcal{N}$. noctiflora pollen while others were incompatible. Further tests with more plants of hybrid origin have shown that there is a considerable variability in the extent of pollen-tube growth under these circumstances. This suggests that $S$ genotypes of interspecific hybrid origin react differently from those of the pure $\mathcal{N}$. alata and, owing to their variable reaction, are unsuitable substitutes for the latter in the study of interspecific compatibility relationships.

\section{(iii) Polymorphic patterns}

The polymorphism of the six incompatibility groups in $\mathcal{N}$. bonariensis, as revealed by the crosses with the five testers, N.l., GM8, $\mathcal{N}$. petunioides, 
$\mathcal{N}$. noctiflora and $\mathcal{N}$. forgetiana, is summarised in table 8 . The six groups show identical patterns of polymorphism in tests with two S.I. species, $\mathcal{N}$. petunioides and $\mathcal{N}$. noctiflora.

There is only one tester species, S.C. $\mathcal{N}$. langsdorffi, with which all the S.I. species studied, including $\mathcal{N}$. alata (Pandey, 1964), show polymorphism. On the other hand, one S.I. species, $\mathcal{N}$. bonariensis, shows polymorphism with all testers (with the possible exception of $\mathcal{N}$. alata).

Considering only the two testers, N.l. and GM8, each of the four species, $\mathcal{N}$. alata (Pandey, 1964), $\mathcal{N}$. petunioides, $\mathcal{N}$. forgetiana and $\mathcal{N}$. noctiflora, shows two polymorphic patterns, whereas $\mathcal{N}$. bonariensis shows all four possible

TABLE 9

The number of polymorphic patterns found in each of the five self-incompatible species when tested with the pollen of two testers, N. langsdorffii and N. glauca strain GM8

\begin{tabular}{|c|c|c|c|c|}
\hline \multirow[b]{2}{*}{ Species } & \multirow[b]{2}{*}{$\begin{array}{c}\text { No. of } \\
\text { polymorphic } \\
\text { patterns }\end{array}$} & \multicolumn{3}{|c|}{$\begin{array}{l}\text { Polymorphic } \\
\text { patterns }\end{array}$} \\
\hline & & &  & $\begin{array}{c}\sigma^{*} \\
\text { GM8 }\end{array}$ \\
\hline $\mathcal{N}$. alata & 2 & $\begin{array}{l}\mathrm{B} \\
\mathrm{D}\end{array}$ & + & - \\
\hline $\mathcal{N}$. petunioides & 2 & $\begin{array}{l}B \\
D\end{array}$ & + & - \\
\hline $\mathcal{N}$. forgetiana & 2 & $\begin{array}{l}\mathrm{B} \\
\mathrm{D}\end{array}$ & + & - \\
\hline $\mathcal{N}$. noctiflora & 2 & $\begin{array}{l}\mathrm{A} \\
\mathrm{C}\end{array}$ & $\overline{+}$ & $\begin{array}{l}+ \\
+\end{array}$ \\
\hline $\mathcal{N}$. bonariensis & 4 & $\begin{array}{l}\text { A } \\
\text { B } \\
\text { C } \\
\text { D }\end{array}$ & $\begin{array}{l}- \\
+ \\
+ \\
-\end{array}$ & $\begin{array}{l}+ \\
\overline{+} \\
-\end{array}$ \\
\hline
\end{tabular}

patterns (table 9). The two patterns of the first four species, however, are not identical. The three species, $\mathcal{N}$. alata, $\mathcal{N}$. petunioides and $\mathcal{N}$. forgetiana, have common patterns, which are different from those occurring in $\mathcal{N}$. noctiflora. The seed materials examined in the present study appear to have related and restricted parentage. It is possible that if more material from different wild sources were examined additional patterns, possibly all four, may be found in each of the S.I. species.

\section{(iv) Self-compatible species as testers}

From one to four representatives of each incompatibility group, including plants of all polymorphic classes, in the three S.I. species, $\mathcal{N}$. bonariensis, $\mathcal{N}$. noctiflora and $\mathcal{N}$. petunioides, were reciprocally crossed with seven S.C. species ( $\mathcal{N}$. paniculata, $\mathcal{N}$. glutinosa, $\mathcal{N}$. sylvestris, $\mathcal{N}$. tabacum, $\mathcal{N}$. rustica, $\mathcal{N}$. suaveolens, and two strains of $\mathcal{N}$. glauca). The results of these crosses, along with those involving N.l. and GM8, are given in table 10 . It will be seen that $\mathcal{N}$. langsdorffi is the only S.C. species whose pollen is acceptable to the styles of at least some of the genotypes of all the S.I. species; pollen of all 


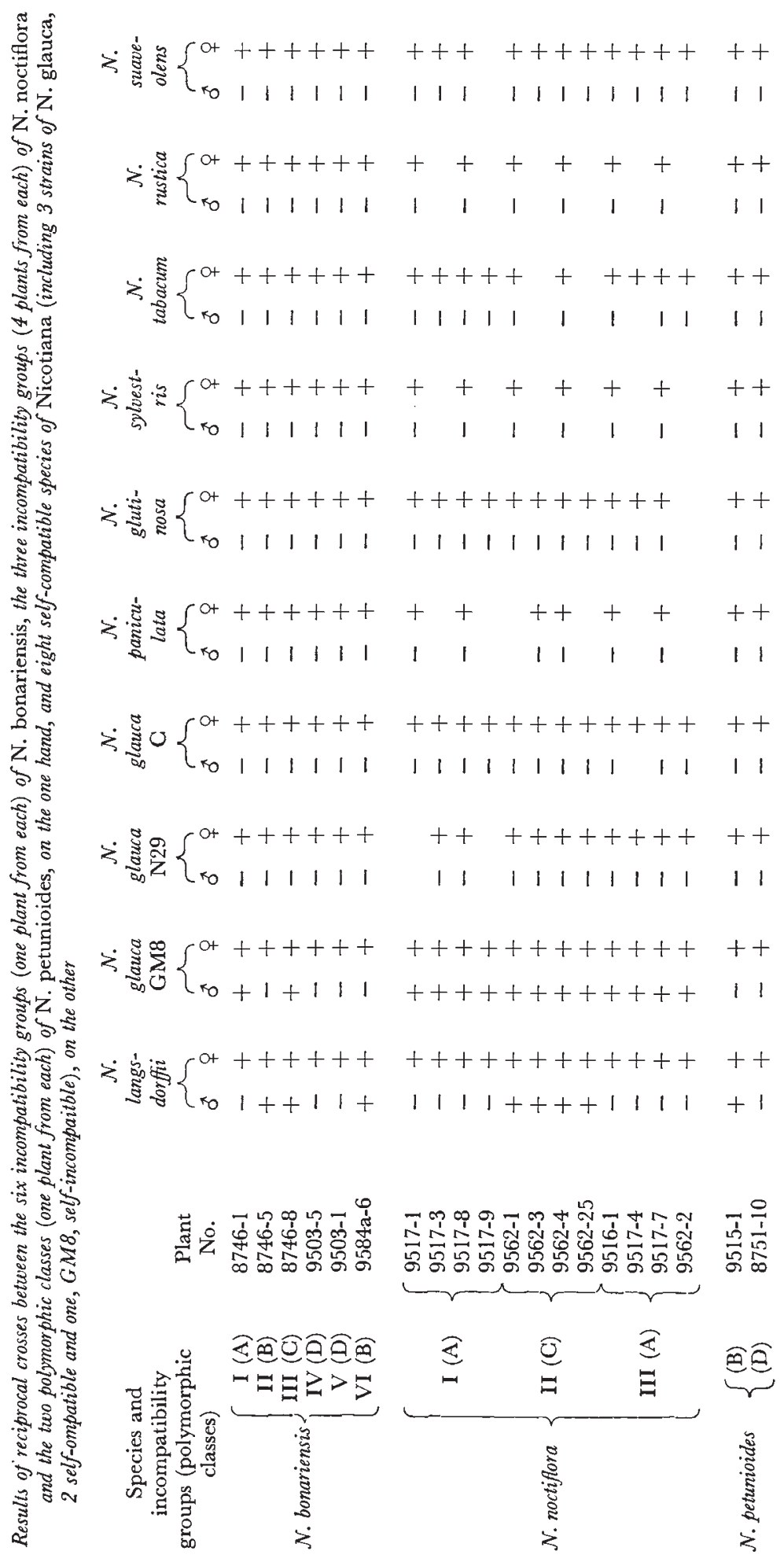


other S.C. species are universally rejected, inhibition usually occurring in the stigma. The reciprocal crosses when the S.I. species are the pollen parents, are all compatible.

In the normally S.C. $\mathcal{N}$. glauca, the S.I. strain GM8 is reciprocally compatible with all genotypes of $\mathcal{N}$. noctiflora, with some genotype of $\mathcal{N}$. bonariensis and with neither of the two genotypes of $\mathcal{N}$. petunioides; whereas, the two S.C. strains, C and N29, are compatible as females and incompatible as males in all crosses. In $\mathcal{N}$. glauca even the self-compatibility gene has been found to show polymorphism in the stylar specificity, styles of the strain C accepting the pollen of $\mathcal{N}$. plumbaginifolia while those of the strain N29 reject it (Pandey, 1968). $\mathcal{N}$. glauca, therefore, is the only species so far studied, in which there is polymorphism in both pollen and stylar specificities; in all other species the polymorphism is limited to the stylar specificity.

\section{Discussion}

One of the basic features underlying the phenomenon of many polymorphisms is the inherent superiority of the heterozygotes over the homozygotes of both kinds, the mutant as well as the original (Ford, 1965). The kinetics of polymorphism may be affected by many factors, but most particularly, by the relative fitnesses of the various genotypes. Genetic polymorphism is thus a state of " active suspense" in which two or more evolutionary forces are so balanced that none gets the upper hand so strongly, or for so long, as to allow the fixation of one allele to the exclusion of the other(s).

The present study of polymorphism of $S$ alleles in Nicotiana has revealed the following features which need special consideration:

(a) Polymorphism usually occurs in the female specificity, the male specificity remaining constant for the whole species. $\mathcal{N}$. glauca is the only species studied in which there is polymorphism in the pollen specificity.

(b) Although in the studies so far, self-compatibility alleles of different specjes were not subjected to the same degree of extensive tests as the selfincompatibility alleles, the limited evidence suggests the rarity of polymorphism in the self-compatibility alleles, the phenomenon being usually restricted to the self-incompatibility alleles.

(c) $\mathcal{N}$. langsdorffi is the only S.C. species with the pollen of which S.I. styles show polymorphism. Pollen containing any other self-compatibility allele occurring in other species is universally rejected by all S.I. styles, the inhibition occurring in the stigma.

\section{(i) Polymorphism in stylar specificity}

The rarity of polymorphism in the pollen suggests that advantageous mutations in the pollen are usually selected to the finish, the mutant pollen replacing the old pollen. Of two kinds of pollen produced by a plant, the pollen with a distinct advantage in pollen-tube growth will be selected with the inevitable exclusion of the other. This will lead to a comparatively rapid rate of fixation of the mutant allele in the pollen. In the style, on the other hand, the mutation may not be selected to the exclusion of the other alleles, and thus polymorphism can occur. The perfect sieving mechanism operating in the styles and the extreme specificity of the pollen and styles may be factors relevant in this connection. 
Another factor possibly responsible for the frequent occurrence of polymorphism in the stylar reaction but not in the pollen is the tissue difference, characteristic of the two organs. The phenomenon of genetic polymorphism is mostly maintained by heterozygous advantage. In a gametophytically controlled incompatibility system this heterozygous advantage can be immediately manifested in the diploid style, a phenomenon not possible in the haploid pollen.

The evolutionary problem posed by the sedentary nature of plants in the creation of genetic variability has been resolved in nature by a compromise, making the male gametes mobile while keeping the female gametes embedded in the sporophyte. Since the transport of the pollen through the aid of natural agencies (air, water) or animals (insects, birds, bats) is largely indiscriminate, the discrimination must occur after the pollen has come in contact with the stigma. It is obvious that the efficiency of the discriminatory process must lie in the development of polymorphism in the style, which deals at once with a large number of pollen grains, rather than in the pollen which acts singly.

Polymorphism of the stylar reaction would appear to be a phenomenon of evolutionary significance, basic to the success of flowering plants. With the evolution of the early anemophilous gymnosperm flower, plants must have faced the problem of protecting their " naked " ovules from the pollen of other related species, which were highly differentiated but whose pollen grains were still capable of growing into the female gametophyte and effecting fertilisation, thus either virtually sterilising the female gametes or producing zygotes inferior to those of their own species. The ability of the female gametophyte to be able to accept the pollen of its own species, while being able to reject the pollen of others which happened to be deposited on it, is so basic to the survival of this evolutionary line of development that the genetic mechanism evolved to overcome this problem may well have been the primitive foundation on which the $S$ complex, as we know it in angiosperms, has developed.

In angiosperms there are two kinds of restriction of fertilisation that may have selective value in a natural population: (1) When two welldifferentiated, related S.I. species come in contact with each other, hybridisation may produce defective hybrids, reduced in reproductive capacity and less fit than either species (Stebbins, 1966). It may also bring about loss of $S$ efficiency thus producing pseudo-self-compatibility in the hybrid, with the resultant inbreeding depression and occurrence of a large number of misfits. Under these circumstances, in the areas of contact between the species, alleles will be selected which, when present in the style, will reject the pollen of the alien species, thus producing polymorphism of $S$ alleles for stylar specificity in both S.I. species. (2) If an S.I. species similarly comes in contact with an S.C. species the resulting introgression is likely to be far more disadvantageous to the S.I. species, which will suffer through inbreeding depression, than to the S.G. species. The maintenance of self-incompatibility in the S.I. species would depend upon the ability of its styles to reject the pollen of the S.C. species (Grun and Radlow, 1961; Pandey, 1962b, 1964). Thus $S$-gene selection in the areas of contact between the S.I. and S.C. species would lead to polymorphism of $S$ genes in the S.I. species, and occasionally in the S.G. species as well. 


\section{(ii) Rarity of polymorphism in the self-compatibility alleles}

Although self-compatibility in an S.I. species may occur either through a variety of changes in the $S$-gene complex or through any other genetic change, the net result is the same: the self-pollen carrying the mutant gamete is able to effect fertilisation while the pollen with the original gamete is unable to do so. While it is possible that in a large species complex occupying a variety of habitats over a large area, different self-compatibility alleles may occur localised in different habitats, the very nature of the phenomenon which allows only that allele to produce seed which has the faster rate of pollen-tube growth, excludes polymorphism within a small population. Here, only one allele, the one which allows the fastest pollen-tube growth, will be fixed rapidly. This fact, along with the fact stated above that the S.C. species usually does not suffer so seriously through introgression as the S.I. species, may account for the relative lack of polymorphism in the selfcompatibility alleles.

\section{(iii) The uniqueness of $\mathrm{N}$. langsdorffii}

Polymorphism of self-incompatibility alleles is found to be more frequent when S.I. species are tested against each other. The only case where S.I. species show polymorphism against an S.C. species is that when the pollen parent is $\mathcal{N}$. langsdorffi. The pollen of all other S.C. species is universally rejected by all S.I. styles.

A clue as to the reason for this uniqueness of $\mathcal{N}$. langsdorffi may be found in the data on general interspecific compatibility relationships in Nicotiana (Pandey, 1968; and unpublished results). A study of 27 species of Nicotiana, including all six S.I. species of this genus, has shown a complex but perfectly systematic pattern of incompatibility. The cross-compatibility relationships could be arranged in such a way that they show a perfect pattern of " stepwise" unilateral incompatibility between species. In this pattern of relationships the S.C. species closest to the S.I. species is $\mathcal{N}$. langsdorffi. Next to $\mathcal{N}$. langsdorffi is $\mathcal{N}$. glauca, which is another exceptional S.C. species having the distinction of showing $S$-gene polymorphism in both pollen and stylar specificities, and with the pollen of which (race GM8) at least one S.I. species, $\mathcal{N}$. bonariensis, shows polymorphism.

Thus the phenomenon of $S$-gene polymorphism, usually limited to the S.I. species, also involves those species which have probably only relatively recently become S.C., and which, therefore, still maintain a close similarity in pollen and stylar specificities with the S.I. species. The conclusion that $\mathcal{N}$. langsdorffi and $\mathcal{N}$. glauca are very close to the S.I. species, as far as the $S$-gene complex is concerned, is also supported by the rare occurrence of S.I. races in both of these species (Goodspeed, quoted by East, 1940; Goodspeed, 1954; Pandey, 1967a).

\section{(iv) Genetic basis of the $S$-gene polymorphism}

For any discussion of the mode of origin of polymorphism in a gene complex, some knowledge regarding the origin of the gene complex itself is essential. On the basis of accumulated evidence from intra- and interspecific incompatibility studies it has been suggested that there are two kinds of specificity, each governed by a separate but closely linked set of genetic elements, involved in the incompatibility reaction-a primary 
specificity controlling interspecific incompatibility and a secondary specificity controlling intraspecific incompatibility (Pandey, 1968). The primary specificity developed early during the evolution of gymnosperms (or preangiosperms) as a means of avoiding indiscriminate fertilisation by anemophilous pollen, thus combating, chiefly, the sterilisation of their " naked" ovules through pollination by relatively distant species, and less significantly, the relatively easy introgression from closely related species. Over these specificities was imposed later, early in the evolution of angiosperms, the secondary specificity as a means of excluding self-fertilisation. The presumed details of such an evolutionary development of specificities will be dealt with in the next paper of this series.

In the course of the evolution of angiosperm flora, many types of mutants of the $S$ complex would have found themselves in advantageous situations, and hence would have been selected and maintained either as fixed genes, or in polymorphic forms. An S.I. plant with all its primary and secondary specificity elements of the $S$ complex intact will reject pollen of all other welldifferentiated species whether S.I. or S.C. The point at which two related S.I. species of a genus would behave as distinct species will, as far as the $S$ complex is concerned, be determined by the extent of dissimilarity of their polygenic backgrounds supporting the activity of the secondary specificity. $S$-specific differentiation occurs when the polygenic differences between the species increase to the extent that the secondary specificity in the pollen of one species is no longer able to interact with the different secondary specificity occurring in the style of the other species, in the manner normal for intraspecific compatible pollination. Under these circumstances, the primary specificity, which normally failed to express itself owing to the intraspecific dominance of the secondary specificity over the primary specificity, is now able to express itself. Provided all primary elements present in the pollen are also present in the style, this will bring about cross-incompatibility. However, in interspecific crosses, as will be seen below, the primary elements are not always evenly matched in the pollen and style.

In angiosperms with selective insect pollination the contamination of stigma by pollen of other species is greatly reduced. In isolated S.I. species having no necessity to safeguard their stigma from the pollen of closely allied species, there would be no selection to maintain all the primary elements. Assuming that the maintenance of the superimposed secondary specificity, controlling intraspecific incompatibility, would not, for reasons of molecular stability, allow too much depletion of the primary specificity, a considerable amount of variability in the primary specificity may still be possible, particularly in those units occupying the outer perimeter of the large, compound, specificity molecule. It is suggested here that the variation in the chain of primary elements in the $\mathrm{S}$ complex is the basis of polymorphism in the self-incompatibility gene. If any primary element which is present in the pollen is absent in the style the cross will be compatible.

\section{(v) Selection producing the S-gene polymorphism}

In S.I. species, mutants of the self-incompatibility gene, involving variability in the primary elements, will have altered interspecific compatibility relationships as compared with those of other alleles, although such mutants will have no effect on intraspecific incompatibility. Certain of these mutant alleles may be advantageous to the species by avoiding introgression, or by 
producing heterozygous advantage, and therefore, would be selected. In most cases these mutations would probably be reversions to the original state the specificity having been lost during the period the population was, isolated. The net result would be polymorphism of self-incompatibility alleles in the stylar reaction.

The extent of polymorphism of a species and the species (\$) with which it shows polymorphism can be a helpful guide in the understanding of its likely evolutionary history as regards the extent of its past distribution and its present taxonomic relationships. Thus the widespread polymorphism against the pollen of the S.C. $\mathcal{N}$. langsdorffi may be attributed to the following causes: (1) Owing to its presumed relatively recent origin of self-compatibility, this species probably still has all the primary elements in the pollen. This allows its pollen to grow down almost any style which has lost one or more elements of the primary specificity. Pollen of other S.C. species in which self-compatibility is of more ancient origin and which, therefore, have their primary specificities seriously eroded, are universally rejected by all S.I. styles. (2) Since introgression of a self-compatibility allele will have serious consequences for an S.I. species, there is a stronger selection pressure against such a gene as compared to genes of other, S.I. species. (3) As this species has a medium flower length for the genus its pollen is capable of penetrating a wide range of stylar lengths occurring in different species. (4) The presumed past occurrence of this species over a wide area has enabled it to come in contact with almost all the S.I. species of the genus which occur in one rather limited area of South America, as compared to the wide distribution of the genus as a whole over three continents, North America, South America and Australia.

The three S.I. species $\mathcal{N}$. alata, $\mathcal{N}$. bonariensis, and $\mathcal{N}$. forgetiana and the S.C. species $\mathcal{N}$. langsdorffi, all belonging to the same taxonomic section Alatae, occur in a more or less common area covering the whole of Uruguay at the southern end, extending on the south-eastern sub-coastal regions of Brazil and including the south-eastern Paraguay, to $20^{\circ} \mathrm{S}$ at the northern end. As expected, all the three S.I. species show polymorphism with $\mathcal{N}$. langsdorffi pollen. However, two other S.I. species $\mathcal{N}$. noctiflora and $\mathcal{N}$. petunioides, belonging to the section Noctiflorae and also showing polymorphism with $\mathcal{N}$. langsdorffi pollen, occur extensively to the south and east of the above region with a belt of land separating these two regions. These two species belong ecologically to the Chilean-Argentine assemblage of species, most of which occupy dry, rocky slopes or sandy, open situations. The four species of the section Alatae, however, belong to another assemblage of species, Uruguayan-Brazilian, which favour stream beds, river banks or margins of woods, and are characteristic of warm temperate regions. Botanical and geological evidence suggests that the two species assemblages, particularly species of the sections Noctiflorae and Alatae with which we are concerned here, had in the past a much wider and common region of distribution including the belt of land from which at present these species are absent (Goodspeed, 1954). In view of these observations the alternative hypothesis, that the polymorphism expressed in relation to the pollen of $\mathcal{N}$. langsdorffi is older than the section Alatae and Noctiflorae and existed in the ancestors of these two sections, is not favoured here.

The occurrence of both $\mathcal{N}$. noctiflora and $\mathcal{N}$. petunioides in the Andes of Prov. Antofagasta, Chile, points to their definition and dispersal as occurring 
prior to the final Andean uplift in Pliocene-Pleistocene (Goodspeed, 1954). Evidence suggests that the distributional separation of the Alatae and Noctiflorae is due to the climatic and ecological consequence of the geological upheavals of Pliocene-Pleistocene, which led to considerable extinction of the flora and extension of some of the populations into present habitats. It would appear, therefore, that the self-compatibility of $\mathcal{N}$. langsdorffi, though recent as compared to that of other self-compatible species of the genus, is probably still early Pleistocene in origin.

In addition to S.C. $\mathcal{N}$. langsdorffi, the S.I. $\mathcal{N}$. bonariensis is of special interest in the context of the present discussion. This species even at present occurs widely throughout the subcoastal Uruguayan-Brazilian region. It must have had a much wider distribution in the past for it shows polymorphism with the pollen of almost all other S.I. species, including those of Noctiflorae. It also shows polymorphism with the S.I. strain GM8 of otherwise S.C. $\mathcal{N}$. glauca, which is a member of the Chilean-Argentine Assemblage and belongs to an altogether different section Paniculatae. The polymorphic relationship, therefore, generally supports the evolutionary and distributional relationship of the species in the sections Alatae, Noctiflorae and Paniculatae, as deduced by Goodspeed (1954) on the basis of the botanical and geological evidence.

\section{(vi) Allelism, polymorphism and the S-gene complex}

Investigations of compatibility relationships have shown that the $S$ gene is involved in the control of at least two, and possibly three, kinds of specific activities. That it controls intraspecific incompatibility with the aid of a large number of alleles is well known. The present work undoubtedly shows that it is also involved in the control of interspecific incompatibility and that the number of alleles at this level is limited, as suggested by the occurrence of identical polymorphism in a number of species. The third type of activity possibly controlled by the $S$ gene, for which there is at present only scanty evidence, is graft-incompatibility (Addison and Tavares, 1952; Evans, 1960). It is significant that these different types of specificities, functioning at three different levels, each with its own specific set of alleles (at least in the case of two sexual compatibilities), should be controlled by the same gene complex. The evolutionary relationships of these specificities are still far from clear, although it is not difficult to visualise a connection between the specificities of the two sexual compatibilities, both of which are expressed through the medium of pollen-style interactions. The graft-incompatibility is quite a different matter, and although any detailed consideration of it at present is premature it is reasonable to assume that it can only be of a vestigial significance, possibly being a relic from a far simpler existence in the remote past, for example from certain lower plants in which sexual compatibility between two organisms is interrelated with their ability to bodily anastomose successfully. It is interesting to note that the $S$ gene in plants appears to offer examples of cryptic as well as apparent polymorphism.

Three independent levels of variability in the $S$-gene complex have now been demonstrated: (1) allelism controlling the differential activity of the pollen and stylar components of the $S$ complex (Lewis, 1951, 1954; Pandey, 1956); (2) allelism controlling intraspecific incompatibility (East and Mangelsdorf, 1925); and (3) allelism controlling interspecific incompatibility (Anderson and de Winton, 1931; Mather, 1943; Pandey, 1964). In view of 
the large-scale genetic polymorphism exemplified by the $S$ gene the concept of the "wild-type" allele may need re-examination. To a classical geneticist most individuals of Drosophila were wild type and a few were mutants. With the better understanding of supergenes (Darlington and Mather, 1949), the concept of wild-type genes must be viewed in the light of various levels of gene frequency, different levels of allelism and a variety of habitats. On the present view of polymorphism different polymorphic, mutant genes of a complex, even those with comparatively low frequencies, will all be considered as wild types since, by definition, polymorphism excludes those variants which are maintained merely by recurrent mutation (Ford, 1940).

The recent detailed studies of the $S$ gene, involving the natural as well as the induced mutated states have confirmed the theory of the $S$-gene complex (Lewis, 1954, 1960, 1964; Pandey, 1956, 1962a, 1964, 1967a, b, 1968). They have brought to light $S$-gene polymorphism on a grand scale, the true mark of a great complex. They have also thrown new light on the organisation, evolution, and antiquity of the $S$ complex. The problem now is to understand more fully the many ramifications of this unique segment of the chromosome which not only plays a major role in the present reproduction of individual species, but appears to have played an even greater role in the evolution of the flowering plants as a whole.

\section{Summary}

1. Four self-incompatible species of $\mathcal{N}$ icotiana, $\mathcal{N}$. bonariensis, $\mathcal{N}$. petunioides, $\mathcal{N}$. noctiflora, and $\mathcal{N}$. forgetiana, show $S$-gene polymorphism similar to that first discovered in $\mathcal{N}$. alata. All five species have two kinds of plants: styles of one accept the pollen of the sister self-compatible species $\mathcal{N}$. langsdorffi, while those of the other reject such pollen.

2. In all cases, where intraincompatible intercompatible groups could be distinguished, polymorphism was strictly associated with the genotypic groups.

3. Similar tests with the pollen of the self-incompatible strain GM8 of otherwise self-compatible species $\mathcal{N}$. glauca revealed polymorphism only in $\mathcal{N}$. bonariensis, certain $S$ genotypes accepting this pollen while others reject it.

4. Crosses between plants of the self-incompatible species revealed wide polymorphism in $\mathcal{N}$. bonariensis.

5. The polymorphism in $\mathcal{N}$. bonariensis was identical in relation to the pollen of two species, $\mathcal{N}$. noctiflora and $\mathcal{N}$. petunioides, different genotypes being either compatible or incompatible with the pollen of the two species alike.

6. Polymorphism in the stylar specificity appears to be widespread while in the pollen specificity it is rare. The only case of the latter was found in $\mathcal{N}$. glauca, in which the pollen of the self-incompatible strain GM8 behaved differently from that of the self-compatible strains.

7. $\mathcal{N}$. langsdorffi is the only self-compatible species with the pollen of which self-incompatible styles show polymorphism; pollen of all other selfcompatible species is universally rejected by all self-incompatible styles.

8. Polymorphism of the $S$ alleles is briefly discussed in relation to the evolution and structure of the $S$-gene complex. It is proposed that the polymorphism of the $S_{\mathrm{I}}$ alleles has developed in response to the selection of those mutant alleles which were still self-incompatible but which were effective in preventing introgression from well-differentiated, related species of the genus. 
9. The taxonomic and distributional relationships of the Nicotiana species involved in the present study are briefly examined in the light of the $S$-gene polymorphism.

Acknowledgments. - I am indebted to Dr L. Corkill, Director, for facilities and encouragement throughout the course of this study. Sincere thanks are also due to Miss A. Laxton for technical assistance in the glasshouse work.

\section{REFERENCES}

ADDison, G., AND TAVAREs, R. 1952. Hybridization and grafting in species of Theobroma which occur in Amazonia. Evolution, 6, 380-386.

ANDERSON, E., AND DE WINTON, D. 1931. The genetic analysis of an unusual relationship between self-sterility and self-fertility in Nicotiana. Ann. Mo. bot. Gdn., 18, 97-116.

APIRION, D., AND zOHARY, D. 1961. Chlorophyll lethal in natural populations of the orchard grass (Dactylis glomerata L.). Genetics, 46, 393-399.

BAKER, H. G. 1954. Dimorphism and incompatibility in the Plumbaginaceae. Proc. 8th Int. Cong. Bot., 10, 133-134.

Burbidge, n. T. 1960. The Australian species of Nicotiana L. (Solanaceae). Aust. F. Bot., 8 $342-380$.

CORKILL, L. 1942. Cyanogenesis in white clover (Trifolium repens L.). V. The inheritance of cyanogenesis. N.Z. Fl. Sci. Technol., 23, 178в-193в.

GROWE, L. K. 1964. The evolution of outbreeding in plants. I. The angiosperms. Heredity, 9, 293-322.

DADAY, H. 1958. Gene frequencies in wild populations of Trifolium repens L. III. World distribution. Heredity, 12, 169-184.

DARLington, C. D. 1958. The Evolution of Genetic Systems, 2 nd ed. Oliver and Boyd, London and Edinburgh.

DARLington, G. D., AND MATHER, x. 1949. The Elements of Genetics. George Allen \& Unwin, London.

Davies, w. E. 1963. Leaf markings in Trifolium repens. In Teaching Genetics (eds. C. D. Darlington and A. D. Bradshaw). Oliver \& Boyd, Edinburgh.

EAst, E. M. 1940. The distribution of self-sterility in the flowering plants. Proc. Amer. Phil. Soc., 82, 449-518.

EAST, E. M., AND MANGELSDORF, A. J. 1925. A new interpretation of the hereditary behavior of self-sterile plants. Proc. Natl. Acad. Sci. U.S., 11, 166-183.

Evans, A. M. 1960. Relationship between vegetative and sexual compatibility in Trifolium. Welsh Plant Breed. Sta. Rep., 1959, 80-87.

FORD, E. B. 1940. Polymorphism and Taxonomy. In The New Systematics (ed. J. Huxley). Clarendon Press, Oxford.

FORD, E. B. 1965. Genetic Polymorphism. Faber \& Faber, London.

GODLEy, E. J. 1955. Breeding systems in New Zealand plants. I. Fuchsia. Ann. Bot., N.S., 19, 549-559.

goodspeed, T. H. 1954. The genus Nicotiana. Chronica Botanica Co., Waltham, Mass.

GRUN, P., AND RADLOW, A. 1961. Evolution of barriers to crossing of self-incompatible with self-compatible species of Solanum. Heredity, 16, 137-143.

LEWIS, D. 1949. Incompatibility in flowering plants. Biol. Revs., 24, 472-496.

LEwTS, D. 1951. Structure of the incompatibility gene. III. Types of spontaneous and induced mutation. Heredity, 5, 399-414.

LEWIS, D. 1954. Comparative incompatibility in angiosperms and fungi. Adv. Genet., 6, 235-285.

LEWTS, D. 1960. Genetic control of specificity and activity of the $S$ antigen in plants. Proc. Roy. Soc., B, 151, 468-477.

LEWIS, D. 1964. A protein dimer hypothesis on incompatibility. In Genetics Today, Proc. XI Int. Congr. Genet. 1963, pp. 658-663. Pergamon Press, London.

MATHER, K. 1943. Specific differences in Petunia. I. Incompatibility. F. Genet., 45, 215-235. PANDEY, K. K. 1956. Mutations of self-incompatibility alleles in Trifolium pratense and T. repens. Genetics, 41, 327-343.

PANDEY, K. K. 1962a. A theory of $S$ gene structure. Nature, 196, 236-238.

PANDEY, к. K. 1962b. Interspecific incompatibility in Solanum species. Amer. J. Bot., 49, 874-882. 
PANDEY, K. K. 1963. Stigmatic secretion and bud-pollinations in self- and cross-incompatible plants. Naturwissenschaften, 50, 408-409.

PANDEY, K. K. 1964. Elements of the $S$-gene complex. I. The $S_{\text {FI }}$ alleles in Nicotiana. Genet. Res., Camb., 5, 397-409.

PANDEY, K. K. 1967a. S gene polymorphism in Nicotiana. Genet. Res., Camb., 10, 251-259. PANDEY, K. K. 1967 b. Elements of the $S$-gene complex. II. Mutation and complementation at the $S_{\mathrm{I}}$ locus in Nicotiana alata. Heredity, 22, 255-283.

PANDEY, K. K. 1968. Compatibility relationships in flowering plants: Role of the $S$-gene complex. Amer. Nat., 102, 475-489.

SMrTH, H. H. 1968. Recent cytogenetic studies in the genus Nicotiana. Adv. Genet., 14, 1-54. stebbins, G. L. 1950. Variation and Evolution in Plants. Columbia Univ. Press, New York. stebbins, G. L. 1966. Processes of Organic Evolution. Prentice-Hall, Englewood Cliffs, N.J. 